\title{
APRENDER A REZAR NA ERA DA TÉCNICA OU "MODOS DE PENSAR A PAZ APÓS AUSCHWITZ"
}

\author{
Juliana Sá \\ (Universidade do Estado do Amazonas)
}

\section{RESUMO}

Aprender a rezar na Era da Técnica (2008), o último volume da tetralogia "O Reino", de Gonçalo M. Tavares, que inclui ainda Um homem: Klaus Klump (2007), Jerusalém (2006) e A Máquina de Joseph Walser (2010a) -, consiste em uma excelente representação da dissolução do território do Mal. No presente texto, realiza-se uma leitura do romance à luz: dos registros históricos da Shoah, experiência inscrita nos anais da Segunda Guerra Mundial; da tese benjaminiana de Estado de Exceção; e, do conceito de literatura de testemunho. Avalia-se, ainda, de que maneira Gonçalo M. Tavares contempla os temas da barbárie, da violência de matriz política e da biopolítica no projeto geral da tetralogia e os desenvolve por meio da representação literária.

PALAVRAS-CHAVE: Guerra; literatura; paz.

\section{RESUMÉ}

Aprender a rezar na Era da Técnica le dernier volume de la tétralogie «O Reino «, Gonçalo M. Tavares, qui comprend aussi Um homem: Klaus Klump (2007), Jerusalém (2006) et A Máquina de Joseph Walser (2010a)- se compose d'une excellente représentation de la dissolution du territoire du Mal. Dans ce papier, nous faisons une lecture de la roman à la lumière de documents historiques de l'expérience de la Shoah, écrite dans les annales de la Seconde Guerre, la thèse de Benjamin d'une l'Etat d'exception et de la littérature de témoignage. En appel, nous évaluons comment Tavares couvre les thèmes de la barbarie, la violence politique et de la biopolitiqué dans le projet général de la tétralogie et développe à travers la représentation littéraire.

MOTS-CLÉ: Guerre; literatura; la paix. 
Mas nem a paz modificará o Homem, claro. Os dados foram há muito lançados.

Fala-se em máquinas de guerra, mas nenhuma máquina é pacífica.

Gonçalo M. Tavares, A Máquina de Joseph Walser

\section{NO PRINCÍPIO, ERA A FORÇA}

Desde os clássicos homéricos, a representação da guerra, da crise e da dor figura como objeto de interesse das artes literárias. Com a incidência da Shoah ${ }^{1}$, entretanto, o interesse por questões que pontuam o horror e/ou a morte se expandiu de tal modo que hoje se registram, entre os principais nomes do cânone literário mundial, autores que investiram na representação do mal-estar pela violência através: do registro da experiência-limite testemunhada, configurando aquilo que autores como Seligmann-Silva (2003) classificam como literatura do trauma; da temática urbana, que privilegia tipos sociais marginalizados e a incursão do homem no universo do crime; ou de uma ficção ligada aos preceitos de uma "estética da guerra moderna" (BENJAMIN, 1994, p. 196). Outros casos de representação mimética se somam a estes.

Na primeira década do século XXI, a Europa anuncia um novo representante da escrita da barbárie. Trata-se de Gonçalo M. Tavares, o profícuo autor da tetralogia O Reino - também chamada dos Livros Pretos - que reúne Um homem: Klaus Klump ([2003] 2007), A Máquina de Joseph Walser ([2003] 2010a), Jerusalém ([2005] 2006) e Aprender a rezar na Era da técnica ([2007] 2008). Seus personagens apontam os limites de uma linguagem em crise $^{2}$, portam-se como sobreviventes de um mal anunciado, reportam-se a um absurdo existencial, que muitas vezes se afirma como, e se passa por, loucura. A "insistência num discurso de cariz filosófico"3 acerca do que os românticos alemães chamaram "espírito dos tempos" (zeitgeist) propiciou que o conjunto da obra de Tavares avançasse a patamares inéditos diante do atual panorama das literaturas lusitanas.

Dentre a numerosa bibliografia de Tavares, que atualmente reúne mais de vinte títulos publicados em todo o mundo, selecionamos os romances d'O Reino por uma razão que julgamos especial: cada título investe em um atributo particular das máquinas bélicas em sua composição - velocidade, força, paciência ${ }^{4}$, precisão - reelaborando um simulacro da retórica particular da guerra e do totalitarismo técnico e científico. Fala-se aqui de um homem consciente dos mecanismos internos do horror, que os aplica com a diligência de um operador industrial - Joseph Walser (2010a) - ou de um perito em técnicas medicinais, tal como Lenz Buchmann e Theodor Busbeck, este, um dos principais personagens de Jerusalém. Os narradores d'O Reino articulam o Mal por dentro de um contexto de guerra cujo instinto primário é mover-se em direção à precariedade dos corpos, das falas, dos impulsos genuinamente humanos. Nestas histórias, nada permanece por muito tempo inalterado. Nem mesmo um local insuspeito como um jardim - que passa a abrigar o desprezo reservado a matérias que não assumem forma metálica e poder de fogo, posto que "a paisagem quando não se transforma em acto [...] é uma coisa que se pisa ou vê" (TAVARES, 2007, p. 100) - constitui-se um elemento inalterado na microfísica dos romances. 
Dentre os títulos observados, Aprender a rezar na Era da Técnica (2008), o último dos quatro em termos de publicação, possui algumas das mais emblemáticas imagens das reverberações da guerra sobre o espírito do homem moderno: a do homem que resiste aos desígnios da morte quando confrontado pela ameaça da doença, assim como daquele que pensa e se posiciona como militar em combate sem jamais ter sido intitulado soldado ou general - a propósito da personagem Lenz.

O mote pelo qual se afirmam as forças fictícias da narrativa é substancialmente o do sistema militar que age em circunstâncias de conflito. Assim sendo, de que outra maneira podemos avaliar a perspectivação histórica da barbárie realizada, sobretudo, através dos narradores d' O Reino, senão pela lógica da tradição bélica que se mantém em nosso século? A qual outro pressuposto histórico atribuir a aguda reflexão crítica de seus personagens, senão ao fato de que "todos os esforços para estetizar a política convergem para um ponto [e] esse ponto é a guerra"? (BENJAMIN, 1994, p. 195).

Este texto se dedicará, portanto, a compreender o mais amplamente possível a representação literária da dinâmica discursiva envolvendo as noções de guerra e de paz articuladas no romance Aprender a rezar na Era da técnica. Para este fim, examinaremos de modo pormenorizado a progressão discursiva do protagonista Lenz Buchmann no interior do romance, desde o discurso técnico, como médico, ao discurso político; consideraremos a performance de Buchmann em relação aos protagonistas das outras obras da tetralogia; e, por fim, refletiremos acerca da representação do horror na obra em questão em contraluz ao processo histórico do século XX.

Nossa investigação terá início no estudo da racionalização do protagonista - amparado pela voz do narrador - em torno da possível relativização dos conceitos de guerra, paz e política. Pelo que nos sugere o romance, o princípio norteador sob o qual Lenz Buchmann age partilha de uma antiga formulação feita por Carl Von Clausewitz (1780-1831), segundo a qual a essência da política e do poder militar se funde na habilidade de abalar as bases que conferem segurança e paz à figura adversária. Em Aprender a rezar..., esta ideia parte do abalo significativo do clima de segurança - ao qual denominamos "tempo de paz" - transmitido pelas estratégias eleitorais empreendidas por Buchmann e Kestner, com vistas a conquistar a presidência do Partido, dentre elas, a de forjar uma ameaça de caos coletivo por meio de explosivos posicionados em monumentos vitais da cidade. Se tomarmos os personagens por alegorias de guerra, teríamos os dois políticos na base do exército de ataque em investida armada contra uma cidade que, nos planos dos antagonistas, assume a posição de alvo em condição vulnerável a um ataque invisível. As sutis armas empenhadas para o combate discriminar-se-ão no decorrer deste texto.

Partindo do princípio de que Lenz, este personagem central do romance e objeto significativo de nossos estudos, acredita dominar os mecanismos a partir dos quais o mal se institui, por proceder de modo eficaz na disseminação do medo na cidade em que vive, refletiremos sobre as premissas textuais e críticas que amparam os objetivos expostos acima. 


\section{CONTEXTO (OU A ENTRADA NO FRONT)}

As máquinas de guerra vêm aí, mas não tenha medo.

O problema não são as máquinas que se aproximam da cidade,

são as máquinas que já aqui estão.

A Máquina de Joseph Walser (2010a)

"Algum pão e algum medo, disse Lenz, em voz alta, por impulso, cortando um longo período de silêncio" (TAVARES, 2008, p. 93). Eis a cena em que doutor Buchmann elabora pela primeira vez o esboço daquilo que, ao fim da primeira parte do romance, se tornaria o discurso condutor de sua política. A proclamação do axioma ocorre durante o episódio da morte de Albert, o primogênito da família Buchmann. Já nesta ocasião, anunciada nas primeiras cem páginas do romance, observa-se a disposição de Lenz para a indiferença à perda. $\mathrm{O}$ evento que, tradicionalmente, representa um estado de luto e recolhimento propicia ao então médico a erupção de uma nova "posição fundamental na ordem do espírito" (TAVARES, 2008, p. 91) e da cidade.

O episódio recém-descrito reúne alguns dos traços principais das personagens masculinas que povoam O Reino. Charles Baudelaire (1996) ao discorrer sobre o caráter estético da obra de Constantin Guys ${ }^{5}$ (18051892), classificado pelo poeta como "o pintor da vida moderna", destaca a reprodução de imagens que remetem a guerras orientais como um dos gêneros temáticos preferidos do artista. Soma-se ao "estudo do militar, do dândi ou mesmo dos animais" (BAUDELAIRE, 1996, p. 27) que compõem suas telas, o estilo sóbrio e elegante pelo qual retrata "Kurdes à Scutari (Curdos em Scutari), tropas estranhas cujo aspecto faz pensar em uma invasão de hordas bárbaras" (BAUDELAIRE, 1996, p. 35). Recorro ao ensaio baudelairiano para compor, em caráter introdutório, algumas impressões sobre os homens de maior destaque da tetralogia de Gonçalo Tavares.

Tal como Guys, Gonçalo Tavares "mostra uma predileção muito acentuada pelo militar, pelo soldado" o que me permite partilhar da crítica do poeta francês e apostar na ideia de que "essa propensão se deve não somente às virtudes e qualidades que passam forçosamente da alma do guerreiro para sua atitude e seu rosto, como também ao paramento vistoso com que sua profissão o reveste" (BAUDELAIRE, 1996, p. 41). À imagem dos soldados e oficiais militares representados na obra de Guy, Lenz Buchmann possui "ares indeléveis de gentlemen, resolutos e discretos, que os distinguem até o fim do mundo" (BAUDELAIRE, 1996, p. 34). Sua imagem traspassa o arquétipo do homem indiferente ao destino de uma guerra, como um Joseph Walser (TAVARES, 2010a, p. 19, 23), mas também não se conforma à figura de um membro engajado da resistência civil, como um Klaus Klump. Estipular ao personagem Lenz a classificação em um destes dois paradigmas conduziria perigosamente esta análise a um procedimen- 
to equívoco. O ponto de convergência de ambos os perfis seria, decerto, a aposta mais aceita para alguém capaz de sorver com tamanha precisão a "terrível poesia de um campo de batalha" (BAUDELAIRE, 1996, p. 35).

Com sensibilidade semelhante à de Constantin Guys, que saía às ruas parisienses a captar da natureza crua e concreta, suas formas e sujeitos, Tavares imprime sob a superfície narrativa as impressões do homem moderno, desenganado, indiferente ao destino do mundo, embora suficientemente sensível para absorver o sentimento de ruína e desgaste inerente à poética da guerra e ainda elaborar uma espécie de contradiscurso em face deste. As sombrias tonalidades de "Troupes de serveur crime" (1854, cf. apêndice) compõem um cenário de homens apoiados na experiência dos campos de guerra, que partilham da dor da sobrevivência, retrato de "uma beleza que decorre da necessidade de estar pronto para morrer a cada minuto" (BAUDELAIRE, 1996, p. 44).

A atividade artefatual interna às cores frias e aos traços sinuosos nos dá a conhecer soldados que abandonam trincheiras para recolher seus mortos, armas e canhões desprezados ao solo, cavalos alvejados em batalha. "O caráter pitoresco da cena, que consiste no contraste da natureza oriental circundante com as atitudes e os uniformes ocidentais da assistência" (BAUDELAIRE, 1996, p. 34), exige um envolvimento da parte do espectador, que diante da representação plástica é incitado a movimentar seus sentidos em direção ao objeto-tema.

A sensação provocada pelos quadros produzidos por Guys entre 1854 e 1856, período em que pôs em cena os anais das guerras do extremo Oriente, nos parece evoluir de um primitivo estado de contemplação - em que se rastreia os efeitos do sublime - para a admiração, a reverência, o respeito e, em última instância, o assombro, uma vez que "a causa do sublime é sempre um modo de terror ou de dor" (BURKE, 1993, p. 141). Deve-se à estética pós-romântica do pintor da vida moderna baudelairiano a expressividade dos homens da guarda militar cuja atualidade moral e estética nos provoca duplo encanto: artístico e histórico (BAUDELAIRE, 1996, p. 14). Por sua invulgar capacidade de transpor para as telas o horror de um campo em guerra, a imponência de seus generais e o sentimento aristocrático de sua época - incorrendo sutilmente em considerações morais, por vezes - Constantin Guys é exaltado por Baudelaire à altura de um digno pintor das multidões. Para o poeta das Flores do Mal, Guys

buscou por toda a parte a beleza passageira e fugaz da vida presente, o caráter daquilo que o leitor nos permitiu chamar de Modernidade. Freqüentemente estranho, violento e excessivo, mas sempre poético, ele soube concentrar em seus desenhos o sabor amargo ou capitoso do vinho da vida. (BAUDELAIRE, 1996, p. 70)

Elementos tais quais esses nos reconduzem a Lenz Buchmann, sobretudo, em face das primeiras imagens construídas a seu respeito no romance: um caçador que ensaia o ritual de caça em seus pormenores, di- 
recionando seu ímpeto dominador a pequenos objetos como botas, armas e um pesado colete. No capítulo "A caça", Lenz age como quem se prepara para enfrentar uma legião, saindo rumo à floresta à procura de um opositor que lhe obrigue a exercer "uma posição em cima da terra, dentro do mapa de combate" (TAVARES, 2008, p. 19-21). A isto se deve certa determinação política que lhe exige um perfeito equilíbrio entre agilidade mecânica e atividade intelectual.

"Lenz, diga-se já não estranhava que o final dos seus pensamentos terminasse em imagens militares" (TAVARES, 2008, p. 107). Como nos quer convencer o narrador, trata-se de "alguém que nascera e fora educado para matar e por um devaneio intelectual decidira exercer a medicina” (TAVARES, 2008, p. 107). Um ditador em formação, adiante interrompida pela doença, a mesma matéria que combatia em corpos estranhos e que lhe foi de singular importância para o ingresso e a saída do cenário político.

Das primeiras experiências relatadas no romance, extrai-se a tensa estrutura de perigo imposta a Lenz pelo pai, Frederich, ainda na infância. Os primeiros sinais de um projeto de dominação pelo medo surgem através de uma prescrição de Frederich aos filhos - Albert e Lenz: manter em regime estável a lucidez e o controle das emoções, sobretudo, as paixões que de algum modo traduzissem medo, covardia ou fraqueza. Lenz é iniciado nos cálculos do horror com disciplina semelhante à de um soldado convocado ao serviço militar. "Nesta casa o medo é ilegal - era uma das frases mais marcantes de Frederich Buchmann. Esta frase, diga-se ainda, fora determinante para Lenz" (TAVARES, 2008, p. 94). Noutro trecho, o narrador recupera o passado dos Buchmann e testemunha o rigor disciplinar a que eram submetidos: "Frederich castigava as manifestações de medo de qualquer dos seus filhos fechando-os à chave num compartimento da casa, 'a prisão', em que tapara as janelas, em que não havia uma única peça de mobília ou objecto” (TAVARES, 2008, p. 94).

Adolescente, pouco seguro de si e ainda com certo grau de resistência - como nos adverte o narrador (TAVARES, 2008, p. 17) -, o filho mais novo da família Buchmann tem, sob as vistas do pai, sua iniciação no combate ao próprio medo. Quando, por imposição de Frederich e tendo este por espectador, Lenz violenta a empregada doméstica (TAVARES, 2008, p.17), uma nova experiência se inclui à sua formação: a crueldade. $\mathrm{Na}$ condição de médico, não se ressente por perdas aleatórias de uma ou outra vida, uma vez que cada novo diagnóstico passa a contar pela lógica do combate ao desprezível, do extermínio ao mais fraco, da intervenção in extremis, seja esta pelo manuseio preciso do bisturi numa cirurgia, seja pela omissão em atender um último pedido de uma paciente em estado terminal (TAVARES, 2008, p. 69-80). Suas escolhas - sobretudo, as duas principais: a de tornar-se médico e, em seguida, político - são dirigidas por uma lógica orgânica que prevê o ordenamento da vida pública e individual pelo domínio da precisão e da técnica (TAVARES, 2008, p. 218-220).

$\mathrm{Na}$ forma do rigor com que assimilara o rígido procedimento moral do pai, o político Lenz reelabora a precisão cirúrgica de médico em favor de uma nova técnica, que já não visa apenas ao domínio sobre qual- 
quer manifestação de fraqueza que viesse a indicar a regulação do medo sobre os seus sentidos. Ao que registra o narrador, sua trajetória não inclui passagem por campos de guerra, como sucedera com o pai, "porém, no fundo, mesmo nos vários anos em que exercera a medicina, Lenz havia sido um militar" (TAVARES, 2008, p. 108). Assim ele acreditava, numa clara manifestação da ética herdada de Frederich: afinal, "Lenz sempre interpretara simples ideias do pai sobre o mundo como declarações inequívocas ou mesmo ordens" (TAVARES, 2008, p. 108). Na indefinição da atmosfera que percorre o romance surgem "indícios do aparecimento de uma nova civilização” (TAVARES, 2008, p. 205-215).

Parte disto a que chamamos "projeto civilizatório" deve-se ao procedimento de "desumanização" das personagens que se acham de alguma forma subjugadas pela autoridade assumida por Lenz Buchmann. Das múltiplas formas de negação da alteridade que o outro representa se extrai a mesma matéria de construção do discurso totalitário que marcou o sistema da barbárie nazista: uma "crueldade implícita nas relações entre aqueles que se supõem 'naturalmente' superiores e seus inferiores supostamente 'naturais"' (HOBSBAWN, 1998, p. 273). Verticalizar o tratamento dado aos “espectadores" (TAVARES, 2008, p. 230-231) da esfera pública da cidade corresponde, em Aprender a rezar..., a estabelecer o "senso de uma superioridade natural [grifo do autor], como se fosse uma superioridade divina ou cosmicamente sancionada de pessoas da cúpula em relação a pessoas da base" (TAVARES, 2008, p. 273). Isto equivale a dizer que o sistema de gestão partidária gerida por Buchmann obedece a uma escalada seletiva de barbárie, na qual agir conforme a lei corresponde a dar uma razão para que os mais fracos não sejam mortos (TAVARES, 2008, p. 195).

Seja através do poder exercido no subcomando do Partido, seja através da relação hostil e vertical que mantém com indivíduos com deficiências ou limitações específicas, como mendigos, loucos e doentes, Lenz se posiciona categoricamente no topo da "hierarquia prática estabelecida entre qualquer homem saudável e qualquer homem doente" (TAVARES, 2008, p. 162). Louco Rafa, Gustav Liebnitz e o mendigo inominado dos primeiros capítulos do romance compõem três dos principais exemplos de corpos frágeis, violáveis e vulneráveis à tirania do legislador, que desafia a supremacia jurídica em favor de sua "doutrina de relação com o mundo" (TAVARES, 2008, p. 168). Para os cidadãos comuns que compõem a cidade, estes sujeitos são inimputáveis de dor, sacrifício ou sofrimento por se julgar que os respectivos castigos já lhes foram imputados por desígnio natural. Para Lenz Buchmann, entretanto, as três figuras se equiparam a matérias desprezíveis em razão da fórmula estranha de desequilíbrio estético e funcional que os diferencia dentre os demais da espécie, apesar de todos os homens da cidade estarem sob a mesma lei e, nos diz o narrador, orgulharem-se disso por completo (TAVARES, 2008, p. 196).

Mas, nos cabe lembrar que Lenz não pertence ao mundo dos que obedecem a leis. "A evidente facilidade com que mandaria matar um pobre pedinte ou aquele bom louco do Rafa sem que isso, por certo, lhe trouxesse qualquer consequência pessoal (...) levava-o a ter um desprezo brutal em relação à ideia de lei” (TAVARES, 2008, p. 196). 
A impostura do último Buchmann em relação ao decoro exigido na função de homem público nos conduz também a outra corrente de análise. À luz da observação da dinâmica geopolítica atual verificamos na ideia de eficácia do biopoder (AGAMBEN, 2008, p. 156) um fundamento válido para se pensar a relação conflituosa de Lenz com os personagens marginais/marginalizados da narrativa, e avaliar as implicações deste conceito sobre a ideia original da campanha do Partido.

De acordo com Agamben, "a ambição suprema do biopoder consiste em produzir em um corpo humano a separação absoluta entre o ser vivo e o ser que fala (...), o não-homem e o homem: a sobrevivência" (AGAMBEN, 2008, p. 156). Quanto a esta proposição, importa esclarecer o sentido aqui atribuído ao termo sobrevivência. Diferente da ideia comum de subexistência, sobreviver, no contexto da biopolítica contemporânea, consiste no ponto para o qual convergem as duas faces da estrutura do poder: uma invisível e outra oculta. Sobrevive aquilo (em matéria de força ou objeto) ou aquele (em termos de sujeito) que conserva sua possibilidade de testemunho, embora invisível em sua própria exposição e/ou destituído de uma identidade aparente. Por esta característica em especial, o biopoder se manifesta, por excelência, como uma substância difusa nas coletividades, que escapa ao olhar e ao exame racional da maioria pela invisibilidade de que se reveste. Daí acreditarmos que, por mais que a origem do Mal perpasse a apreensão dos habitantes da cidade de Aprender a rezar... (2008), "um conjunto de forças não contabilizáveis" (TAVARES, 2008, p. 241) lhes rondavam sob a forma de uma ameaça inominável.

Também encontramos no caráter coercitivo das biopolíticas uma possível resposta para a precariedade dos laços sociais tecidos entre Lenz e os personagens marginais da trama. Tomamos por objeto de análise a reflexão de Agamben sobre um "tipo" humano fundamental para entendermos a complexa dinâmica dos agentes militares em campos de extermínio com seus prisioneiros: o muçulmano. Assumir a condição de muçulmano consiste em reduzir-se à "figura-limite de uma espécie particular, em que perdem sentido não só categorias como dignidade e respeito, mas até mesmo a própria ideia de um limite ético" (AGAMBEN, 2008, p. 70). Testemunhar o sofrimento dos muçulmanos se constitui numa tarefa tão traumática que os sobreviventes dos campos de concentração se recusam a sequer mencioná-los. Hannah Arendt (1906-1975) por diversas vezes se recusou a descrever em pormenores os exercícios de tortura e violência a que os muçulmanos foram submetidos nos campos, creditando ao evento o título de "fabricação de cadáveres" (idem, p. 77). “[...] os deportados renunciam de uma vez para sempre a falar do muçulmano, como se o silêncio, o não-ver, fosse no momento a única atitude adequada para quem habita além de qualquer ajuda" (idem, p. 70).

"Para o muçulmano, testemunhar, querer contemplar a impossibilidade de ver não é uma tarefa simples" (AGAMBEN, 2008, p. 61). Semelhante aos prisioneiros de Auschwitz, que aos olhos dos comandantes dos campos de extermínio eram vistos como "uma improvável e monstruosa máquina biológica, isenta não apenas de qualquer consciência moral, mas até mesmo de sensibilidade e de estímulos nervosos" (AGAMBEN, 2008, p. 64), o vagabundo que pacata e sistematicamente assiste às relações sexuais 
de Lenz com Maria Buchmann assume - mesmo por defesa estratégica a invisibilidade como contrapartida à intimidade de que era cúmplice. $\mathrm{O}$ espectador "[...] teve de despojar-se tão inteiramente do respeito e do amor próprios, de seus sentimentos e de sua personalidade que, para todos os efeitos, não passava de uma máquina que funcionava apenas quando seus superiores lhe apertavam os botões de comando" (BETTELHEIM apud AGAMBEN, 2008, p. 64). A esta descrição relaciono o episódio "Medir o Mal" (TAVARES, 2008, p. 57-59), em que Lenz mais uma vez recebe o mendigo em casa, inicia uma conversa enquanto dá-lhe água e comida, chama-lhe a atenção para o objeto que tem em mãos - a radiografia do irmão Albert - porém, o vagabundo, indiferente ao "diálogo", sente-se confortável na posição de espectador, recusando dispensar alguma sincera atenção, ou mesmo, investir legítimo interesse nas provocações do médico-anfitrião.

"O muçulmano é não só, e nem tanto, um limite entre a vida e a morte; ele marca, muito mais, o limiar entre o homem e o não-homem" (AGAMBEN, 2008, p. 62). Louco Rafa, ao submeter-se a visitar a casa de Lenz, expõe-se à condição fundamental do muçulmano que não reage diante da iminência do perigo. Diferente do vagabundo, que deliberava cada gesto, passo e olhar em favor da esmola que almejava receber ao fim da visita à casa dos Buchmann, Rafa não hesita ou se espanta diante do convite para tomar parte na relação sexual de Lenz com a mulher, Maria. A loucura do sujeito constitui-se, para Lenz, na justificativa ideal para a indiscrição de narrar cada detalhe do ato sexual. O comportamento do louco contrasta firmemente com o silêncio praticado pelo vagabundo que somente assiste, não participa, não toma parte no evento (TAVARES, 2008, p. 234-236).

No entanto, a categoria em que reunimos a classe de sujeitos secundários do romance também se aplica àquele que se punha à frente da hierarquia político-social da cidade, buscando comandar seu destino, deixando viver e fazendo morrer (AGAMBEN, 2008, p. 88) quem quer que esteja envolvido nos cálculos do poder soberano. Em seus últimos meses de vida, Lenz toma parte na experiência opressora de duas significativas perdas: a da dignidade, em seu sentido mais literal, ao ser privado do poder sobre seu próprio corpo quando em avançado estado de doença; e, da perenidade do poder político, de que é privado logo após o anúncio agressivo da doença.

No instante em que ambas as perdas se agregam, formando a mais grave ameaça ao poder supremo do vice-presidente do Partido, Lenz "se transforma [...] em uma espécie de muçulmano 'bem nutrido e bem vestido' que continua a vestir-se e a alimentar-se bem” (AGAMBEN, 2008, p. 64). Embora tenha arriscado, por mais de uma vez, manter a força que o distinguia como notável homem público, investindo contra os principais monumentos da cidade (TAVARES, 2008, p. 283-286), Lenz inexoravelmente avança rumo ao ponto que demarca a fronteira entre a vida e a morte, entre o homem e o não-homem, e é inserido no estado de coisas que costumava observar nos homens que julgava fracos e vulneráveis. Manter-se humano, em termos morais, trata-se de "conseguir conservar dignidade e respeito de si" (AGAMBEN, 2008, p. 63) diante de uma circunstância opressora e humilhante, desafio que Buchmann, limitado pelo corpo, não consegue vencer. 


\section{AO ATAQUE! SOBRE O LANÇAR BOMBAS}

Isso não é um livro, é uma pequena bomba.

Queres perturbar tanques com prosa?

Um Homem: Klaus Klump (2007)

$\mathrm{Na}$ combinação das técnicas de regulação da consciência coletiva com a substituição dos conflitos violentos por demonstrações de força e repressão, estava "a ideia que baseava toda a campanha de Kestner, o candidato a presidente do Partido" (TAVARES, 2008, p. 211). A fórmula elaborada por Lenz é clara: a técnica empregada como médico nas cirurgias em que investia o bisturi contra o tecido do corpo individual seria, agora, redirecionada ao corpo da cidade na condição de político. Mudava-se o organismo, mas o procedimento permanecia o mesmo: manipular a desordem instalada por uma ameaça invisível.

Para Lenz, o terror parece ser o instrumento que melhor atende à formulação de um "poder coercitivo capaz de constranger os homens a [...] confiar no conselho e na autoridade [...] dos homens eloquentes" (LIMONGI, 2007, p. 135, 144, 145). Importa, entretanto, destacarmos a que qualidade de terror fazemos referência.

Diz Jacques Rancière que

o terror não é simplesmente um medo mais forte que responde a uma ameaça mais temerosa e difusa. É uma maneira de nomear, de ressentir e de explicar o que causa perturbação na alma de cada um de nós, assim como na ordem mundial. É uma maneira de definir os princípios da ordem e as razões da desordem. (RANCIÈRE 2007, p. 53)

Em Aprender a rezar..., mapeamos as duas principais formas assumidas pelo medo enumeradas por Rancière: o horror em seu tratamento clássico e a mais recente configuração do terror, datada, sobretudo, a partir do traumático acontecimento de 11 de setembro de 2001.

A forma clássica dada ao horror se manifesta através do agenciamento pleno dos sentidos que norteiam as paixões de cada simples cidadão. Do evento que marca a explosão de parte do teatro principal, seguida pela morte de um transeunte do lugar, se retira a matéria necessária para instalar um estado permanente de tensão, tal como a sensação provocada pelo terror secreto que comanda ficções como Sobre meninos e lobos (RANCIÈRE, 2007, p. 58). À frente deste cenário que simula um ambiente de guerra está Lenz, "o famoso portador da mão direita que destrói para depois construir à sua maneira" (TAVARES, 2008, p. 205). O desconhecimento da causa, ou ainda, a mirada vaga daquilo que constitui a origem do incidente trabalha a favor do medo que paralisa a ação de combate dos cidadãos, fazendo deles meros espectadores do fenômeno.

Quanto ao segundo tratamento dado ao medo descrito por Rancière, voltamo-nos ao clima de terror entre os cidadãos que se constituiu, em pouco tempo, o principal objetivo perseguido pelos "dois homens fortes" (TAVARES, 2008, p. 146) do Partido: "Sem o ter calculado, Buchmann 
conseguira algo que nem cem mil acções políticas concretas poderiam dar: conquistar a atenção, simultaneamente, do instinto do medo e do instinto de compaixão dos outros" (TAVARES, 2008, p. 245).

Certos da posição que ocupam na hierarquia social da cidade, Lenz e Kestner movimentam o "medo dos poderes invisíveis" (TAVARES, 2008, p. 146), através de uma "sutilíssima estratégia retórica [que tem por] intuito convencer seus contemporâneos" a confiarem seus votos ao Partido sob a promessa de assegurar a paz ameaçada pela degradação de patrimônios públicos da cidade (TAVARES, 2008, p. 240-243, 283-286).

Apesar da aparente complexidade do projeto de Lenz Buchmann e Hamm Kestner, de "instalar o estado de tensão na cidade" (TAVARES, 2008, p. 240), os mecanismos empregados para este fim obedecem a uma lógica já observada por outro habitante d'O Reino. Em que pesem as singularidades do propósito de explosão do teatro principal, outro narrador da tetralogia - o intermediador de A Máquina de Joseph Walser - nos adverte que "a técnica de influenciar os homens assustando-os com o que ainda não existe é antiga" (TAVARES, 2010a, p. 11). Contudo, como num diálogo entre os dois narradores, o processo de barbarização é descrito em Aprender a rezar... de modo a evidenciar uma pretensa atualidade metodológica:

Primeiro, construir um perigo sem origem identificável; depois, com isso, forçar o movimento da população; por fim, preparar o estado forte do qual sairiam dois tipos de pessoas: as que protegem e as que são protegidas. Eis as tarefas que estavam na mesa do seu mundo (TAVARES, 2008, p. 241).

Se, em Um homem: Klaus Klump e A Máquina..., a guerra se enuncia de forma inequívoca com a presença de tanques, corpos e militares nas ruas, em Aprender a rezar...o alerta de um perigo iminente é neutralizado pela ação da política, que torna a substituir a aplicação de violência explícita contra um inimigo declarado por artifícios políticos de difícil rastreamento. A propósito, a estratégia de produção do terror urbano se revela eficiente na medida em que se mantém anônima a sua fonte perante o discernimento popular. A "experiência estratégica pelas guerras de trincheiras" (BENJAMIN, 1994, p. 198) mostra toda a sua eficácia na medida em que é submetida a uma paisagem em que tudo parece inalterado até ser brutalmente surpreendido por um medo que "arrancava as coisas da sua imobilidade" (TAVARES, 2008, p. 223).

\title{
3. A PAZ COMO EXCEÇÃO: A CONTRAOFENSIVA
}

\author{
"há uma guerra bem mais forte e bem mais alta,/ \\ porém os generais ainda não se perceberam" \\ Uma Viagem à Índia (2010b)
}

A trajetória histórica da ciência política moderna nos mostra que o direito à liberdade individual representa, no contexto dos Estados democráticos modernos, uma das principais premissas dos direitos civis e fator elementar para a manutenção dos governos republicanos. Contraditoria- 
mente, porém, a configuração atual das políticas de relações internacionais nos principais países do eixo europeu e norte-americano nos remete a estruturas de poder que afrontam as bases democráticas, reduzindo ao máximo (e sob aparente clima de paz) a participação popular. Acerca desse cenário geopolítico, Agamben (2007) revisita a tese de que o "estado de exceção [... ] tornou-se regra" (BENJAMIN, 1994, p. 226), sob o enfoque da conjuntura política do século XXI, durante o qual a tese benjaminiana se confirma por se apresentar "muito mais como uma técnica de governo do que como uma medida excepcional, mas também deixa aparecer sua natureza de paradigma constitutivo da ordem jurídica" (AGAMBEN, 2007, p. 18).

A crítica do pensador italiano dialoga com outra recente análise realizada pelo pesquisador brasileiro Joel Birman, em Cadernos sobre o Mal (2009). Para Birman, as táticas de regulação extensiva, bem como o cenário de intolerância e insegurança produzido após o 11 de setembro nos Estados Unidos, inserem-se num contexto mais amplo, ao qual classifica como a era da "pax americana" (BIRMAN, 2009, p. 132, grifo do autor). Nesta, "as exceções foram se impondo e acabando com as ilusões cultivadas acerca dos novos tempos de concórdia universal” (BIRMAN, 2009, p. 130).

O “progresso da civilidade ocorrido desde o século XVIII até o início do XX [e] obtido preponderantemente ou em sua totalidade sob a influência do Iluminismo" (HOBSBAWN, 1998, p. 270) experimentou o declínio com o assombro filosófico provocado pelas catástrofes do último século. Diante da real impossibilidade do projeto iluminista - que previa "acabar definitivamente com o tempo das trevas" (BIRMAN, 2009, p. 129) para que a paz pudesse ser instituída -, a barbárie passa a assumir em nosso tempo o caráter de "colapso geral da civilização" (HOBSBAWN, 1998, p. 271).

Outro efeito da "reversão do que poderíamos chamar de projeto do Iluminismo do século XVIII” (HOBSBAWN, 1998, p. 269) foi a conversão dos tempos de concórdia mundial pela substituição progressiva da paz, em seu sentido original, em trégua, um estado superficialmente similar ao primeiro.

Acreditando ser "a paz [...] uma das grandes utopias do Ocidente, desde o século XVII" (BIRMAN, 2009, p. 129), Birman nos coloca diante do ideário histórico da paz, discutido, sobretudo, nos postulados iluministas de Kant acerca da filosofia do direito. Apoiado na matéria epistemológica do tratado kantiano de paz perpétua, o autor resgata a ideia de estabelecimento pleno da paz através do triunfo da razão sobre a "minoridade do entendimento", que teria na guerra um de seus principais exemplos. Contudo, este resgate se dá numa abordagem diacrônica, que analisa os valores iluministas na contraluz do processo histórico que culminou nas atuais formas de governo. Segundo Birman, "tudo o que nos aconteceu se realizou no itinerário oposto ao da paz perpétua. A razão instrumental fez escolhas que foram efetivamente na contramão dos ideais do Iluminismo, de maneira que a barbárie foi a resultante maior dessa tradição" (BIRMAN, 2009, p. 30). 
A atual configuração da política mundial aponta, de fato, para uma direção oposta àquela sentenciada por Kant no remoto século XVIII. Mesmo destituídos do argumento medieval que versava a necessidade de expansão ultramarina como fator político-econômico para efeitos de domínio territorial e consolidação de fronteiras ${ }^{6}$, os principais polos econômicos da atualidade constroem para si outras necessidades. Tais necessidades nos colocam diante de outra observação. A propósito do termo, diz Agamben que "uma opinião recorrente coloca como fundamento do estado de exceção o conceito de necessidade" (AGAMBEN, 2007, p. 40). Aplicada à leitura do romance em questão, esta categoria contribui para o entendimento do que vem a ser o substrato da consciência de Buchmann acerca dos perigosos mecanismos políticos que aplica na cidade. "Mais do que tornar lícito o ilícito, a necessidade age aqui como justificativa para uma transgressão em um caso específico por meio de uma exceção" (AGAMBEN, 2007, p. 40-41). (A exemplo disto, lembremos do episódio do assassinato de Louco Rafa e Maria Buchmann, praticado por Lenz.) "A teoria da necessidade não é aqui outra coisa que uma teoria da exceção (dispensatio), em virtude da qual um caso particular escapa à obrigação da observância da lei” (AGAMBEN, 2007, p. 42).

Se, por um lado, Aprender a rezar... representa simbolicamente a metáfora hobbesiana da saída do homem de um estado de natureza (JASMIN, 2007, p. 112), no qual a experiência do conflito - seja físico ou espiritual - estaria suspensa por um ordenamento que lhe é superior, por outro, notamos que esta passagem de estado parece ainda não se realizar em Um homem: Klaus Klump. Como se originado num momento anterior à narrativa de Lenz Buchmann, o primeiro título da tetralogia transmite as exatas sensações descritas por Hobbes em sua reflexão política acerca das consequências coletivas do medo na esfera pública: cada personagem do romance, seja este homem ou mulher, lúcido ou louco, todos "são igualmente aptos a matar e, por isso mesmo, vivem a ameaça de um estado caótico, de anomia total, de ausência de regras comuns e cuja expressão mais aguda é a guerra de todos contra todos" (JASMIN, 2007, p. 112).

Enquanto o narrador de Klaus Klump nos situa num cenário de guerra declarada, onde "as armas são o que resta de uma série de instrumentos e experiências" (TAVARES, 2007, p. 45), a voz onisciente que nos transmite as sensações e a trajetória de Buchmann nos dirige - a pretexto do projeto geral da tetralogia, já dito - por caminhos em que se entrecruzam índices de uma guerra superada e/ou prestes a eclodir.

Semelhante ao quadro observado na crítica de Agamben (2007) acerca da sistemática dos governos republicanos de nosso século, o modelo político previsto por Lenz Buchmann se aplica como uma espécie de laboratório no qual se experimenta e se aperfeiçoa o biopoder e outros "dispositivos funcionais do estado de exceção como paradigma de governo" (AGAMBEN, 2007, p. 19). A "transferência de capacidades da medicina para a política” (TAVARES, 2008, p. 161) abre ao novo membro do Partido 
"dois campos da existência" (TAVARES, 2008, p. 141), que o permitiam ver a cidade segundo a lógica dos Estados beligerantes, onde a massa civil representa "uma decadência em pleno esforço, que não descansa, que não tem domingos" (TAVARES, 2008, p. 147).

\section{RESTOS, RASTROS E RUÍNAS: O PÓS-GUERRA}

Mas não perca a perspectiva histórica. Mesmo dentro de um escritório, fechados à chave (...), cheios de calor e com este barulho das máquinas, mesmo aqui, nesta situação, não nos devemos esquecer da História.

A Máquina de Joseph Walser (2010a)

De Thomas Mann ${ }^{7}$, escritor e crítico alemão que documentou suas impressões da catástrofe do exílio norte-americano, a Primo Levi, sobrevivente e memorialista da Shoah, autor de É Isto um Homem? (2000), as paisagens da barbárie, da maneira como hoje são retratadas pela memória ocidental, anunciam um estado de luto que, passadas seis décadas desde a trégua anunciada em 1945, ainda persiste no seio da cultura pós-moderna.

Diante da atualidade deste estado de luto, diz Seligmann-Silva, acerca de "nossa capacidade de (re)inscrever os traços deixados pelo passado" (SELIGMANN-SILVA, 2003, p. 78), que: "Não existe discurso que esgote a dor, não existem palavras que recubram a "experiência" de Auschwitz, não existe explicação para a animalização do homem", mas, ainda assim, "é necessário escrever a história desse período" (SELIGMANN-SILVA, 2003, p. 15). Acerca disso, acrescento: não somente escrevê-la - trazê-la à memória de nosso tempo a pretexto de um "resgate de consciência" da barbárie de que toda a humanidade foi cúmplice - mas também permitir que, através dos recursos da ficção, ofereça-se ao escritor pós-Auschwitz a liberdade para exercer a "faculdade de intercambiar experiências" (BENJAMIN, 1994, p. 198), assumindo para si a tarefa de "escovar a História a contrapelo" (BENJAMIN, 1994, p. 225).

Se "narrar o trauma real" (SELLIGMAN-SILVA, 2003, p. 371) na literatura que não se quer testemunhal representa lidar com a possibilidade de (re)criar sobre o caráter arbitrário da História, encontramos no romance a que se dedica este texto a configuração precisa da revisão alegórica das imagens do horror. Em Aprender a rezar..., o espírito conturbado das catástrofes históricas é recuperado como vulto, do qual nenhum personagem ou mesmo o ambiente narrativo dá a nitidez e os contornos esperados por um leitor de romances pretensamente históricos.

O apagamento dos índices - nomes, datas e lugares - histórico-sociais, outrora privilegiados por estéticas realistas ${ }^{8}$ de que temos informação, nos deixa diante de uma narrativa ao mesmo tempo esquiva e me- 
morial. Esquiva, dizemos, em virtude da sagacidade com a qual o narrador simula diante de nós uma linearidade cronológica que, progressivamente, perde em espaço e relevância para a lucidez reflexiva que, ao fim, passa a dominar a narrativa. A respeito desta observação, voltamos a Benjamin , em sua décima quarta tese acerca d"“O Narrador", em que condensa o que nos propomos a dizer afirmando que "somente o romance... separa [...] o essencial e o temporal", de modo que, "toda a ação interna do romance não é senão a luta contra o poder do tempo" (BENJAMIN, 1994, p. 212). Por outro lado, chamamos "memorial" ao romance de Tavares em ocasião do encontro possível entre a ficção e a consciência histórica conservada em trechos pontuais da narrativa, tais como esse: "os factos históricos, acreditava Lenz, a história no seu sentido mais amplo, para além do que mostrava, tinha ainda uma série de movimentos que se faziam atrás das costas" (TAVARES, 2008, p. 184).

A despeito da ausência de fatos que ocasionalmente lhe pudessem conferir a credencial de uma legítima testemunha da Shoah ${ }^{9}$, o autor revela por intermédio das personagens da tetralogia $O \operatorname{Reino}^{10}$ a legitimidade particular de testemunhas secundárias, aquelas que reelaboram o cenário e as vozes dos sobreviventes da experiência-limite da guerra sob a licença da poiesis. Neste contexto especial em que se forma a ficção da Shoah, a apropriação do testemunho original oportuniza ao autor reelaborar a História na forma do discurso mimético, que, embora prescinda da fidedignidade aos fatos, não se distancia da essência da matéria histórica, a qual assimila como essencial à memória da origem do testemunho. Sob esta condição, a literatura de testemunho secundário, categoria na qual incluímos Aprender a rezar na Era da técnica, adquire "a validade de que necessita" (AGAMBEN, 2008, p. 149) para esquematizar um discurso que se quer novo e original.

A memória do trauma depara-se, no entanto, com uma aporia estabelecida pelos próprios limites da ética pós-Shoah ${ }^{11}$ : a impossibilidade da linguagem em dar conta de uma realidade inenarrável. A respeito disto, retornamos uma vez mais às palavras de Benjamin, que simultaneamente nos indaga e esclarece: "Não existem, nas vozes que escutamos, ecos de vozes que emudeceram? [...] Se assim é, existe um encontro secreto, marcado entre as gerações precedentes e a nossa" (BENJAMIN, 1994, p. 223).

\section{PARA EFEITO DE CONCLUSÃO}

Se nos fosse permitido sintetizar num único tema o espírito predominante na tetralogia $O$ Reino, este, certamente, seria o de um mal-estar em excesso. Excesso de imperativos - que dominam em absoluto a práxis de Lenz Buchmann mesmo antes de seu ingresso na esfera político-partidária. Excesso do Mal, especialmente na forma da crueldade ${ }^{12}$ que caracteriza a ambientação do romance protagonizado por Klaus Klump e que alcança - em graus variáveis - os personagens de A Máquina de Joseph Walser e Jerusalém. 
Nos quatro títulos, a guerra figura como matéria comum e seus efeitos atuam de modo significativo na formação da moratória civil, do Estado e dos princípios éticos que regem os valores das personagens. É por assim pensar que relacionamos a atmosfera de horror visualizada na tetralogia de Gonçalo M. Tavares ao fenômeno da Shoah, esta grande catástrofe representada no Terceiro Reich. Servimo-nos da oitava tese "Sobre o conceito da História" de Walter Benjamin (1994) para avalizar nosso argumento de que há em Aprender a rezar... referências passíveis de correspondência com a experiência-limite da Shoah. Muito embora não haja alusão específica ao evento, é possível relacionar seus mecanismos de dissuasão do medo e do terror a partir dos discursos de seu protagonista, que simbolicamente evoca a memória de Auschwitz por via de seus idealizadores.

Dentre os principais temas observados na tetralogia O Reino, a afirmação relacional entre exercício de poder e instrumentalização do medo como força de racionalização política, concentrados em Lenz Buchmann, destacam-se sobre os demais conceitos presentes em Aprender a rezar... pela superior capacidade de transposição do universo da narrativa para a realidade extrema na qual se configura a posição do homem pós-Auschwitz.

Como na tetralogia $O$ Reino, a memória "dos que não viveram o terror da guerra na carne"13 se constrói na atualidade através da intensa ocorrência de guerras irregulares lideradas pelas atuais potências do imperialismo econômico. Aprender a rezar na Era da técnica coordena bem este exemplo. Nele, se localiza não apenas uma consciência histórica dos eventos bélicos pelo caráter combativo de suas personagens, como também um discurso clínico sobre a tradição do redemoinho do horror, no qual todos tomamos parte.

Observando atentamente as particularidades do romance, pudemos visualizar uma nítida progressão discursiva na fala de Lenz Buchmann. A visão político-filosófica descrita na infância se intensifica durante a mudança da função de médico para homem político e se completa na condição de prestigiado vice-presidente do Partido. Permeia os estágios finais desse discurso também o inerente sentimento de decadência do corpo e do espírito de Buchmann, que acompanha a degradação de sua meta na carreira política, sempre com apurada perspectiva racional.

Por estas razões, investimos na obra de Gonçalo M. Tavares. Vislumbramos no conjunto dos quatro volumes de sua tetralogia uma excelente representação da dissolução do território do mal ${ }^{14}$, uma vez que, apesar da nacionalidade de seu autor, o romance protagonizado por Lenz Buchmann se concentra em categorias extraídas da experiência humana ampla da guerra, isto é, o mal enquanto elemento caro ao universo totalitário e o medo inerente às relações de poder, introduzindo o autor no hall sem fronteiras dos escritores pós-Auschwitz. 


\section{REFERÊNCIAS BIBLIOGRÁFICAS}

AGAMBEN, Giorgio. Estado de exceção. 2. ed. Trad. Iraci D. Poleti. São Paulo: Boitempo, 2007.

O que resta de Auschwitz: o arquivo e a testemunha (Homo Sacer III). Trad. Selvino J. Assmann. São Paulo: Boitempo, 2008.

BAUDELAIRE, Charles. Sobre a modernidade: o pintor da vida moderna. Trad. Teixeira Coelho. Rio de Janeiro: Paz e Terra, 1996.

BENJAMIN, Walter. Magia e técnica, arte e política. (Obras escolhidas vol I) Trad. Sérgio Paulo Rouanet. São Paulo: Brasiliense, 1994.

BIRMAN, Joel. Cadernos sobre o Mal: agressividade, violência e crueldade. Rio de Janeiro: Civilização Brasileira, 2009.

BURKE, Edmund. Uma investigação filosófica sobre a origem de nossas idéias do sublime e do belo. Trad. Enid Abreu Dobránszky. Campinas: Papirus, 1993.

DELUMEAU, Jean. A história do medo no Ocidente 1300-1800: uma cidade sitiada. Trad. Maria Lúcia Machado. São Paulo: Companhia das Letras, 2009.

FERREIRA, António Manuel. Breve apontamento sobre a poesia de Gonçalo M. Tavares. In: Diário de Aveiro, 3 Junho de 2003. Disponível em: $<$ http://www.dlc.ua.pt/classicos/Gtavares.pdf>. Acesso em 20 out de 2010.

HOBSBAWN, Eric. Barbárie: manual do usuário. In: Sobre História: ensaios. Trad. Cid Knipel Moreira. São Paulo: Companhia das Letras, 1998. pp. 268-280.

JASMIN, Marcelo. O despotismo democrático, sem medo e sem Oriente. In: NOVAES, Adauto (org.). Ensaios sobre o medo. São Paulo: Editora SENAC; Edições SESC, 2007. pp. 111-133.

LEVI, Primo. É isto um homem? Trad. de Luigi Del Re. Rio de Janeiro: Rocco, 2000.

LIMONGI, Maria Isabel. A racionalização do medo na política. In: NOVAES, Adauto (org.). Ensaios sobre o medo. São Paulo: Editora SENAC; Edições SESC, 2007. pp. 135-152.

MANN, Thomas. Ouvintes alemães!: discursos contra Hitler (19401945). Trad. Antonio Carlos dos Santos; Renato Zwik. Rio de Janeiro: Jorge Zahar, 2009.

NOVAES, Adauto. Política do medo. In: (org.). Ensaios sobre o medo. São Paulo: Editora SENAC; Edições SESC, 2007. p. 9-16. 
RANCIÉRE, Jacques. Do medo ao terror. In: NOVAES, Adauto (org.). Ensaios sobre o medo. São Paulo: Editora SENAC; Edições SESC, 2007. p. 53-71.

SELIGMANN-SILVA, Márcio (org.). História, memória, literatura: o Testemunho na Era das Catástrofes. Campinas: Editora da Unicamp, 2003.

TAVARES, Gonçalo M. Aprender a rezar na Era da técnica: posição no mundo de Lenz Buchmann. São Paulo: Companhia das Letras, 2008.

. Um homem: Klaus Klump. São Paulo: Companhia da Letras, 2007. . Jerusalém. São Paulo: Companhia da Letras, 2006.

A máquina de Joseph Walser. São Paulo: Companhia das Letras, 2010a.

. Uma viagem à Índia: melancolia contemporânea (um itinerário). São Paulo: Leya, 2010.

(Recebido para publicação em 03/11/2011,

Aprovado em 30/11/2011)

\section{APÊNDICES}

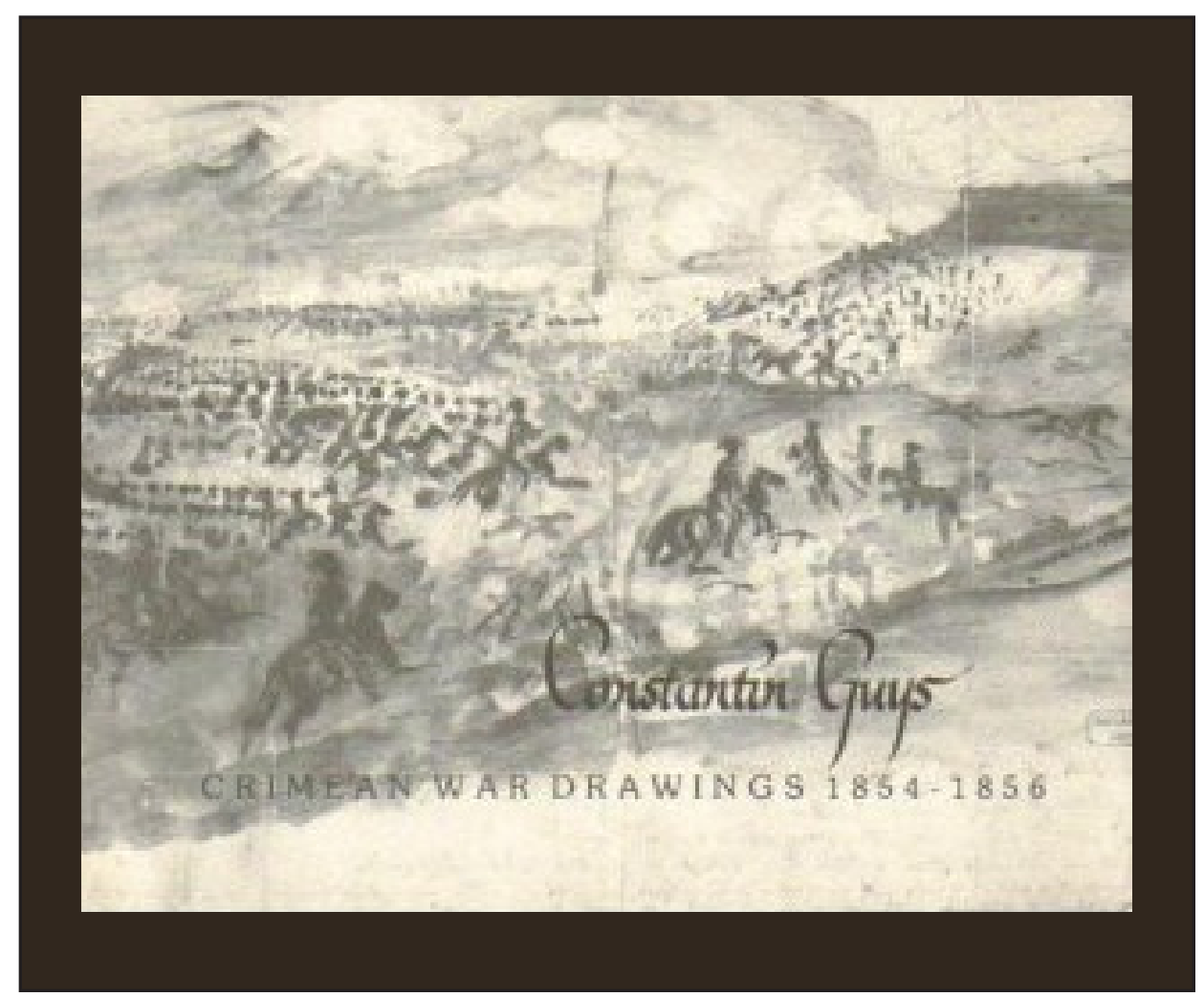

(APÊNDICE - Figura I) Constantin Guys

Crimean War Drawings (1854-1856)

170 GBPYL - Revista do Núcleo de Estudos de Literatura Portuguesa e Africana da UFF, Vol. 4, n 8, Abril de 2012 


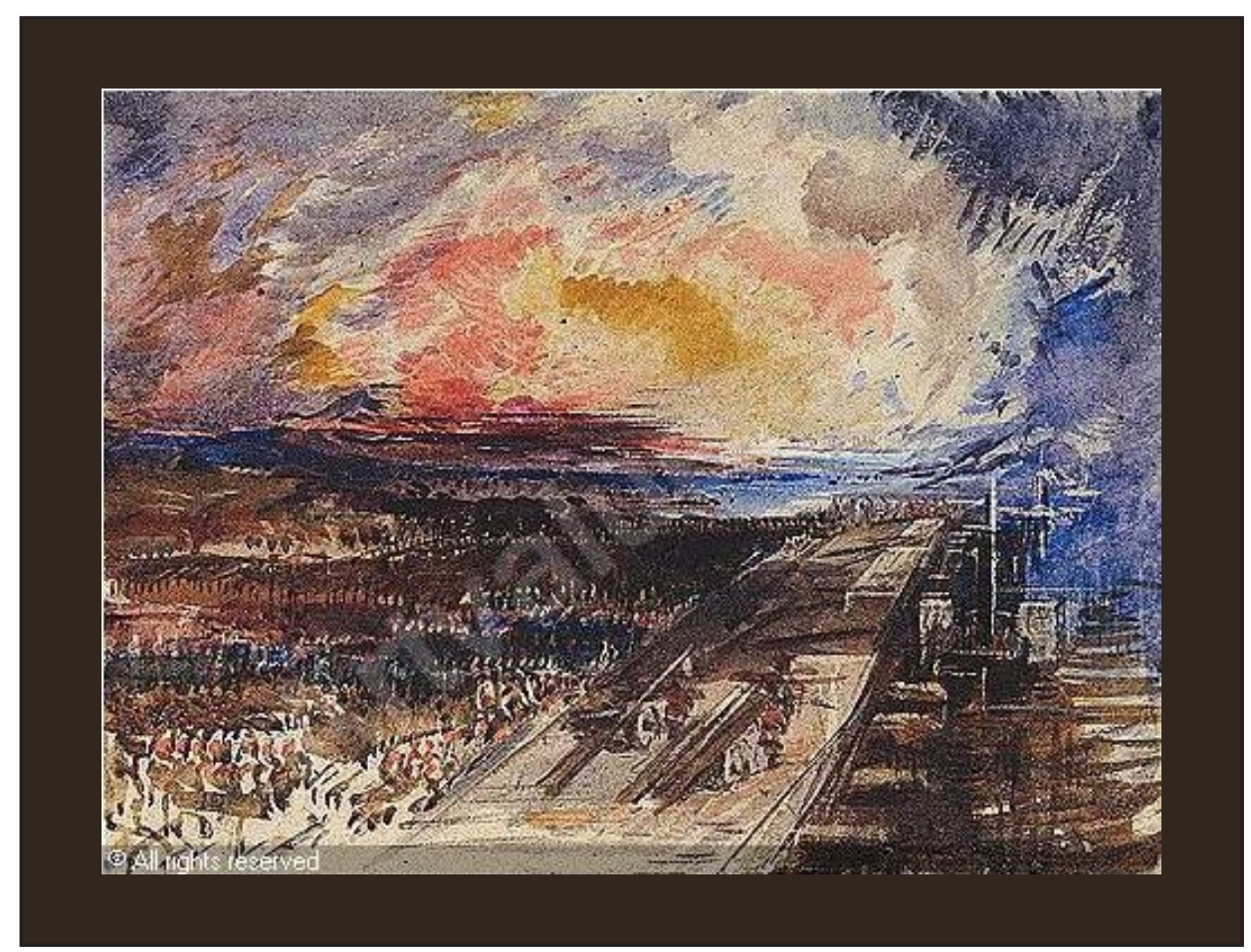

(APÊNDICE - Figura II) Constantin Guys -

Scene from the crimean war (1854)

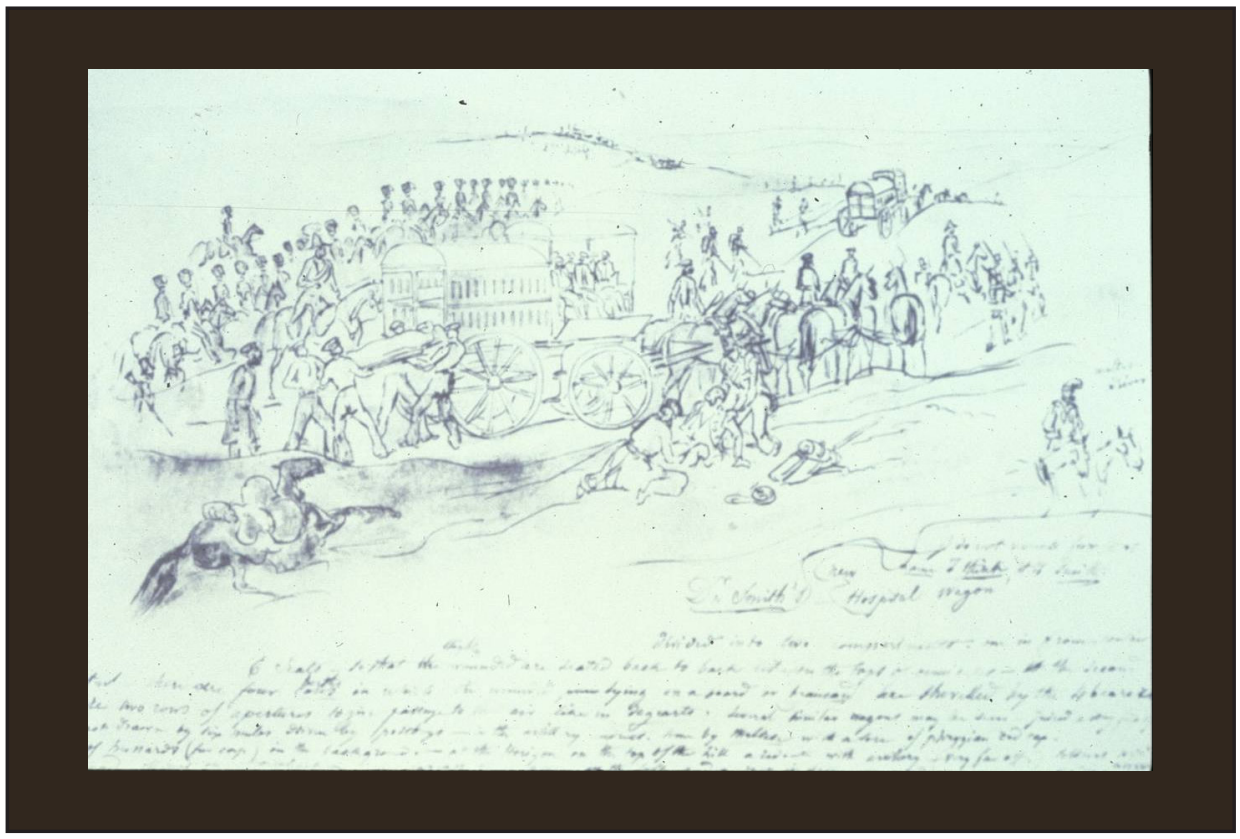

(APÊNDICE - Figura III) Constantin Guys

Troupes der serveen crime (1854) 


\section{NOTAS}

1 Termo utilizado pela comunidade judaica em referência à catástrofe genocida perpetrada durante o regime totalitário nazista. Neste texto, adotaremos a terminologia em questão, empregando Shoah em substituição a Holocausto.

$2 \mathrm{O}$ personagem de Haas Busbeck atende perfeitamente a este diagnóstico (TAVARES, 2006, p. 133-134).

3 Expressão de António Manuel Ferreira (Universidade de Aveiro) em "Breve apontamento sobre a poesia de Gonçalo M. Tavares" (p. 2), Diário de Aveiro, 3 de junho de 2003.

4 Atribui-se a Gonçalo M. Tavares a classificação dos três primeiros atributos enumerados. Depoimento registrado na entrevista concedida pelo escritor ao portal Saraiva Conteúdo, no dia 25 de novembro de 2010.

5 Desenhista, aquarelista e gravador do século XX homenageado no artigo "O pintor da vida moderna”, incluído no volume L'Art Romantique, uma coletânea de artigos de crítica de arte, publicados postumamente em 1869.

6 Em relação a este argumento, destacamos os estudos de Jean Delumeau (2009) sobre o compromisso histórico das coletividades com a instrumentalização do medo a pretexto de uma dada atividade colonizadora.

7 A propósito deste registro, indicamos a leitura de Ouvintes Alemães! (MANN, 2009).

8 A respeito da estética à qual me dirijo, conferir a nota de Seligmann-Silva (2003, p. 373).

9 Para Seligmann-Silva (2003), a testemunha legítima, também chamada de primária, "indica a pessoa que atravessou uma provação, o sobrevivente" (p. 374). Diferente do gênero ficcional a que Aprender a rezar... pertence, a "literatura de testemunho não se trata mais de imitação (grifo do autor) da realidade, mas sim de uma espécie de 'manifestação' do 'real'” (p. 382).

10 Bem como pelo mote comum aos quatro romances, qual seja, o mal e suas variantes dramáticas.

$11 \mathrm{~A}$ "ética do respeito ao outro [que] em vez de negar a violência inerente às relações humanas, trata de responder a ela" (SELIGMANN-SILVA, 2003, p. 14).

$12 \mathrm{E}$ aqui destaco a análise atual e relevante de Joel Birman acerca do tema, que inspirou a criação de um capítulo especial em seu Cadernos sobre o Mal (2009).

13 Expressão de Márcio Seligmann-Silva, em referência às testemunhas secundárias, empregada na palestra "Testemunho da Shoah e Literatura" proferida na X Jornada Interdisciplinar sobre o ensino da história do Holocausto, realizada em 17 de outubro de 2009 na Universidade de São Paulo (USP).

14 Tema este que nos foi objeto de interesse e investigação em projeto de pesquisa de iniciação científica, concluído em 2010. 